\title{
Risk Factors for Problem Gambling Among Indigenous Australians: An Empirical Study
}

\author{
Nerilee Hing • Helen Breen • Ashley Gordon • Alex Russell
}

Published online: 2 February 2013

(C) Springer Science+Business Media New York 2013

\begin{abstract}
Despite a long history of gambling amongst many Indigenous peoples, knowledge about contemporary Indigenous gambling is sparse. In Australia, previous studies of Indigenous gambling have been severely limited in number, scope and rigour. The research reported in this paper is based on the first Indigenous-specific quantitative gambling research undertaken in Australia since 1996 and draws on the largest sample to date. This study examined numerous aspects of gambling among Indigenous Australians. After appropriate consultations and permission, the study collected surveys from 1,259 self-selected Indigenous adults in 2011 at three Indigenous festivals, online and in several Indigenous communities. This paper draws on these data to identify problem gambling risk factors by comparing selected socio-demographic characteristics, early exposure to gambling, gambling motivations, gambling behaviour, gambling cognitions, and substance use while gambling, amongst non-problem, low risk, moderate risk and problem gamblers. A logistic regression investigated the difference between problem gamblers and all other PGSI groups. Risk factors associated with being a problem gambler were: being older, commencing gambling when under 10 years old, always being exposed to adults gambling as a child, using alcohol and/or drugs while gambling, having family and friends who gamble, having an addiction to gambling and not gambling to socialise, having a high expenditure on commercial gambling, and living in a state or territory other than NSW or QLD. Public health measures to address these risk factors are identified.
\end{abstract}

Keywords Problem gambling $\cdot$ Risk factors · Indigenous Australians · Aboriginal

Despite evidence that some Indigenous populations have participated in gambling for several hundreds or even thousands of years (Binde 2005; Breen 2008), little detailed historical knowledge about Indigenous gambling exists. Indigenous peoples today have access to increased gambling opportunities (Gainsbury and Breen 2013; McMillen and

N. Hing $(\bowtie) \cdot$ H. Breen · A. Gordon · A. Russell

Centre for Gambling Education and Research, School of Tourism and Hospitality Management,

Southern Cross University, PO Box 157, Lismore, NSW 2480, Australia

e-mail: nerilee.hing@scu.edu.au 
Donnelly 2008); however, knowledge about most aspects of contemporary Indigenous gambling is also sparse. This limited research is reflected in inadequate culturally sensitive public health interventions for Indigenous gamblers, despite growing awareness that gambling problems appear more widespread in Indigenous than in non-Indigenous populations in some developed nations (Alegría et al. 2009; Belanger 2011; Gray 2011; Ministry of Health 2009; Williams et al. 2011), including in Australia (Cultural and Indigenous Research Centre Australia [CIRCA] 2011; Hare 2009; Queensland Department of Corrective Services 2005; Stevens and Young 2009).

Substantial progress has been made to prevent and address gambling problems amongst non-Indigenous populations. However, significant gaps in preventative, protective and rehabilitative strategies exist for Indigenous gamblers. Examining differences within Indigenous populations between groups of gamblers experiencing differing degrees of problem gambling severity can identify associated risk factors to inform appropriate public health measures.

This paper draws upon data collected in a broader empirical study examining gambling amongst Indigenous Australians from a range of different locations but predominantly from New South Wales (NSW) and Queensland (QLD). The paper aims to identify problem gambling risk factors by comparing selected socio-demographic characteristics, early exposure to gambling, gambling motivations, gambling behaviour, gambling cognitions, and substance use while gambling, amongst non-problem, low risk, moderate risk and problem gamblers. This research is the first Indigenous-specific quantitative gambling research undertaken in Australia since 1996 and draws on the largest sample to date.

\section{Background}

In Australia, the proportion of Indigenous people is around $2.5 \%(548,370$ people) and is growing at over twice the rate of the non-Indigenous population (Australian Bureau of Statistics [ABS] 2010, 2012). Compared to non-Indigenous households, Indigenous households are generally larger, have more dependent children and often include extended kin. The Indigenous Australian population is younger and many (68\%) live in regional and remote areas (ABS 2006), reflecting historical controls confining Indigenous groups to reserves and missions usually away from urban areas (Martin 2008). Cyclical effects of high unemployment and poverty contribute to elevated psychological distress levels and poor physical health for many (ABS 2010; Holland 2011). Such factors may create conducive conditions for gambling for the opportunities it can provide to make ends meet and to escape disadvantage. In fact, populations with higher problem gambling rates tend to have lower socio-economic status (Ministry of Health 2009; Williams et al. 2011), including people who live in poverty, are on welfare, unemployed, homeless and with limited education (Shaffer and Korn 2002; Volberg 1994).

\section{Problem Gambling Amongst Indigenous Peoples}

International research has generally found higher problem gambling rates amongst Indigenous than non-Indigenous populations, including amongst Maori and Pacific Islanders in New Zealand (Gray 2011; Ministry of Health 2009), Aboriginal Americans (Alegría et al. 2009; Welte et al. 2007; Westermeyer et al. 2005) and Aboriginal Canadians (Belanger 2011; Williams et al. 2011; Wynne and McCready 2005). These studies have estimated Aboriginal problem gambling rates at between 10 and $20 \%$ or 2-5 times higher than for the general population. 
No studies have accurately identified problem gambling prevalence amongst Indigenous Australians. While Stevens and Young (2009) suggest a national problem gambling prevalence rate of $13.5 \%$ for Indigenous Australians, this estimation is based on 6 years old secondary data and on self-assessment of others' gambling problems. General population surveys have found statistically significant overrepresentations of Indigenous peoples amongst problem gamblers (Hare 2009; Queensland Government 2008) but their telephone survey methodologies likely underestimate problem gambling by biasing their samples towards more affluent Indigenous respondents with home telephones.

Allowing for small, often unrepresentative samples of Indigenous people and using different screening tools and methods, Indigenous origin appears to be a risk factor for gambling problems. However, little is known about problem gambling risk factors within this population.

\section{Risk Factors for Gambling Problems Amongst Indigenous Peoples}

Surveys with 222 Indigenous Australians in two NSW urban and regional locations found that high gambling expenditure, being younger, single, male or unemployed, and earning less than AUD\$10,000 per annum were problem gambling risk factors (Dickerson et al. 1996). In contrast, some studies have found that Indigenous women are more likely to experience gambling problems than Indigenous men (Dion et al. 2010; McMillen et al. 2004; Queensland Department of Corrective Services 2005; Stevens and Young 2009).

In an Indigenous Australian study with over 160 interviews, Breen et al. (2011) found that generational exposure to gambling, learning about gambling at home, and normalisation of youth gambling were risks for gambling-related problems. Other risks included parental absence, low education, historical gambling norms and reciprocal obligations. Similarly, in a study of 926 high school students in Canberra Australia (Delfabbro et al. 2005), the 32 Indigenous students made up a large proportion of the problem gambler group. They gambled more than their peers, had lower age at onset, and were more likely to have family and friends experiencing gambling problems. Thus, overall exposure to gambling also appears a problem gambling risk factor and may be heightened by the extended family, kin and community relationships amongst Indigenous peoples. These extended networks may also heighten childhood exposure to gambling which can also pose risks (Smith et al. 2011; Tse et al. 2010). In New Zealand, some Maori women socialised into gambling as children repeated this with their children by gambling at home (Morrison 1999). Early exposure to gambling and early gambling onset were reported as risks for Indigenous people in Canada (Smith et al. 2011) and Australia (Hunter and Spargo 1988; McDonald and Wombo 2006).

Household composition, especially living in a group household, has been identified as a risk for regular and problem gambling (Stevens and Young 2009). Living in overcrowded, multi-family households also increases the chance of being affected by gambling-related problems, either by the need for money or by demand sharing. Indigenous Australians in remote regions, where households are larger, generally report more gambling problems than in non-remote regions (Stevens and Young 2009).

The Queensland Government (2010) noted that Indigenous people may gamble to win to obtain additional funds to offset rising living costs. In northern NSW, Indigenous participants reported that to win and to socialise were equally important gambling motivations, although gambling to win was reportedly more common amongst more committed gamblers (Breen et al. 2011). A widespread belief in winning is held by many Indigenous gamblers (QLD Government 2010). Erroneous beliefs about control over luck and winning 
have been found as risk factors in other Indigenous gambling research (Cultural Perspectives 2005; Perese et al. 2005).

Comorbid disorders also elevate the likelihood of gambling problems. In New Zealand, problem gamblers were more likely to be high alcohol consumers, smoke cigarettes daily, have mood or anxiety disorders and report worse self-rated health (Ministry of Health 2009), especially Maori problem gamblers (SHORE and Whariki 2008). Problem gamblers admitted to hospital following a suicide attempt were also more likely to have alcohol problems and be Maori (Penfold et al. 2006). In Canada, alcohol, drug and nicotine dependence have been associated with problem gambling amongst some First Nations groups (Smith et al. 2011). Similarly, for Indigenous Australians, Delfabbro et al. (2005) reported that problem gambling amongst high school students was highly related to substance use, while Breen et al. (2011) suggested gambling while consuming alcohol and/or drugs is a risk.

In summary, studies have identified numerous risk factors for problem gambling amongst Indigenous peoples, but many have been based on qualitative self-report or bivariate correlations of quantitative data. This study is the first to empirically test for problem gambling risk factors amongst Indigenous Australians, while using multivariate techniques to account for possible cross-correlations.

\section{Methods}

\section{Research Design}

Research into any aspect of Indigenous peoples should be congruous with and guided by Indigenous worldviews (Atkinson 2002; Martin 2008). This study's methodology was underpinned by Indigenous guidance and informed by three sets of ethical guidelines (Australian Institute of Aboriginal and Torres Strait Islander Studies [AIATSIS] 2012; National Health and Medical Research Council [NHMRC] 2003, 2007). Ethical and intellectual issues were discussed and negotiated with several Indigenous health services and the Aboriginal Health and Medical Research Council of NSW (AHMRC). The project was approved by the AHMRC (760/10) and a university Human Research Ethics Committee (ECN-10-178).

Based on these ethical research principles, the methodology was developed through respectful consultation with the study communities, incorporating meetings with community leaders, Elders, local Indigenous organisations, boards of directors, event organisers, state and national Indigenous organisations and other stakeholders in an evolving process. One of our research team is an Indigenous Australian but all members were involved in these consultations. Employment of 33 local Indigenous people as research personnel contributed to reciprocity, responsibility and equality. Practical activities were undertaken to help those with gambling problems and provide community education on the impacts of gambling, adhering to principles of protection, spirit and integrity. This process contributed to upholding the researchers' obligations relating to Indigenous principles of research.

\section{Setting, Sampling and Data Collection}

Because the study aimed to measure gambling behaviour, quantitative methods were adopted. Three data collection methods were used to administer an anonymous, voluntary survey.

First, 33 local Indigenous people were recruited and paid as university employees to collect data at three Indigenous cultural and sports festivals under research team 
supervision. The research assistants were trained in survey work, record-keeping, assisting respondents, safety, security, confidentiality and anonymity. Pairs of research assistants approached festival goers, explained the research aims and asked them to complete the gambling survey. If people agreed, they were given a survey and self-sealing envelope which, after completion, was placed in a secure box. Using this approach, 276 surveys were completed at the one-day Saltwater Freshwater Festival (SW/FW) in NSW with an estimated 2,000-5,000 attendees, mostly Indigenous people. An additional 499 surveys were completed at the four-day NSW Aboriginal Rugby League Knockout, attended by 5,000-10,000 Indigenous people. A further 353 surveys were collected from the three-day First Contact Sport and Cultural Festival in QLD, which attracted 3,000-5,000 people.

Second, using research team contacts, over 65 Indigenous community leaders and community agency representatives were asked to publicise the survey in their communities. Each contact was sent posters, surveys and pre-paid return envelopes. This effort yielded 66 completed surveys returned by mail. Third, the survey was placed online with links from Indigenous health, education, employment, responsible gambling and gamblinghelp websites and a Facebook advertisement. This effort yielded 79 completed surveys.

Random draw prizes of $\$ 200$ shopping vouchers were offered to respondents, one at each festival and one every 2 months for mail and online respondents. In total, 1,273 completed surveys were collected. Six respondents did not indicate their age while eight respondents indicated they were aged under 18 years. These 14 surveys were excluded from further analysis. Thus, the following analyses are drawn from 1,259 respondents. As discussed in a previous paper (Hing et al. 2013), the results should be interpreted with the following caveats in mind-the convenience, non-random sample which may not be representative of all Australian Aboriginal adults and possible skewness of the sample to those with higher English literacy.

\section{Instrument Development}

The survey instrument was developed from past gambling surveys, recent research findings and community consultations. Gambling behaviour questions asked about participation, frequency, duration and expenditure on card gambling, frequency of gambling on 10 forms of legal commercial gambling, and usual duration, venue and expenditure for most frequent commercial gambling activity, all within the previous 12 months. To measure gambling motivations, 19 items were adapted from a national survey and survey of problem gamblers in treatment (Productivity Commission 1999) and the Queensland Household Gambling Survey 2006-07 (Queensland Government 2008). Respondents indicated their endorsement of each motivation item on a 'yes-no' scale. Erroneous beliefs about gambling were measured using four items adapted from the Productivity Commission (1999) and the Queensland Government (2008) to which respondents indicated 'yes', 'no' or 'don't know'. Age at first gambling was measured using a five-point ordinal scale ranging from 'less than 5 years old' through to '18 years or older'. Childhood exposure to gambling was also measured using a five-point ordinal scale for to the question "When you were a child growing up, did any of the adults in your household gamble?" The prevalence of non-problem, low-risk, moderate-risk and problem gambling was measured using the PGSI using standard scoring and cut-off points (Ferris and Wynne 2001). Two questions, one on alcohol and drug use while gambling and one on gambling more while under their influence, were measured using PGSI standard responses. Socio-demographic questions were adapted from the Australian Census (ABS 2006). 
Data Analysis

Data were analysed using SPSS v20 on an Apple Intel MacBook Pro. Analyses were conducted using an alpha of 0.05 (unless stated otherwise). Independent samples t-tests, ANOVA and Chi square were used. Where post hoc tests were required, Tukey HSD procedure was used for ANOVA, while examining standardised residuals was employed for Chi square, where a standardised residual of $>|2|$ indicates a significant difference, or a z-test using the Bonferroni correction was applied. Card game pot size information was collected using an open-ended question and variance for this variable was large, so a nonparametric test was employed. Effect sizes for significant results are reported throughout.

\section{Sample Characteristics and Analysis}

Most respondents (92.2\%) reported that they were of Aboriginal origin, $3.8 \%$ indicated they were of Torres Strait Island origin and $4.0 \%$ identified as both. Age groups between 35 and 64 years of age were slightly overrepresented in the sample, while those under 34 and older than 65 were slightly underrepresented compared to $\operatorname{ABS}(2006)$ figures, $\chi^{2}(10, N=1,109)=$ 57.0, $p<0.001, \Phi=0.23$. The age bracket of 18-19 was excluded from this analysis, as comparable figures Australia-wide were not available from the ABS. Females comprised $58.4 \%$ of the sample, compared to $50.2 \%$ Indigenous females from census data (ABS 2006), $\chi^{2}(1, N=1,176)=31.51, p<0.001, \Phi=0.16$. There were no significant differences between the genders in terms of age-group breakdown, $\chi^{2}(11, N=1,168)=17.71, p=0.09$, $\Phi=0.12$. The most frequent marital status was never married (42.9\%), married (24.3\%) and living with a partner $(23.4 \%)$. The majority $(62.6 \%)$ reported that work is their primary source of income, while $30.1 \%$ depended on a pension.

Amongst the 1,256 respondents, $248(19.7 \%)$ reported not gambling on any of the eleven different forms. Thus, $80.3 \%$ had gambled in the past year. On average, respondents took part in $3.47(S D=2.93)$ different gambling activities.

\section{Results}

\section{Prevalence of Problem Gambling}

The PGSI was completed by 964 gamblers (76.6\% of the sample). The scale showed high reliability (Cronbach's alpha $=0.94)$.

Amongst all respondents $(N=1,259), 23.4 \%$ were non-gamblers, $28.0 \%$ non-problem gamblers, $12.5 \%$ low risk gamblers, $16.6 \%$ moderate risk gamblers and $19.5 \%$ problem gamblers. Of the 964 gamblers who completed the PGSI, $36.6 \%$ were classified as nonproblem gamblers, $16.3 \%$ as low risk gamblers, $21.7 \%$ as moderate risk gamblers and $25.4 \%$ as problem gamblers. Thus, nearly two-thirds $(63.4 \%)$ of the gamblers were at some level of risk from their gambling, with approximately one-quarter having serious problems.

\section{PGSI Demographic Comparisons}

Male gamblers were more likely to be at some risk of problem gambling (68.6\%) compared to females $(60.2 \%$ ), with a higher proportion of males in moderate risk and problem gambling categories, $\chi^{2}(3, N=908)=16.19, p=0.001, \Phi=0.13$. 
Separated/divorced/widowed respondents appeared more at risk than other marital statuses, $\chi^{2}(9, N=908)=24.42, p=0.004, \Phi_{\mathrm{C}}=0.10$, while those relying on pension income (either wholly or partially) appeared more at risk than those relying on income from work alone, $\chi^{2}(9, N=907)=21.51, p=0.01, \Phi_{\mathrm{C}}=0.09$. There were no significant differences between the groups in terms of age brackets. For all demographic findings, effect sizes were quite low, indicating a small, possibly inconsequential effect.

\section{Early Onset of Gambling}

Amongst the problem gamblers, $52.1 \%$ commenced gambling before they were of legal age, 18 years. This rate can be compared with $38.0 \%$ of moderate risk gamblers, $29.9 \%$ of low risk gamblers and $20.4 \%$ of non-problem gamblers starting gambling as youths $\chi^{2}$ $\left.(12, N=940)=84.71, p<0.001, \Phi_{\mathrm{C}}=0.17\right)$.

\section{Motivations for Gambling}

Gamblers were asked 19 questions about their motivations for gambling, such as "It helps me to relax", each requiring yes/no answers. Gambling for pleasure and fun was the most common motivation (61.9\% of gamblers), followed by the chance to win extra money $(55.0 \%)$, helps to relax (46.5\%) and socialise with family and friends (44.9\%).

Significant differences between PGSI groups were found for every motivation surveyed. For almost all motivations, the highest proportion of gamblers who endorsed each motivation comprised those classified as problem gamblers. However, for three motivations-socialise with family and friends, chance to win extra money, and pleasure and fun-moderate risk gamblers had the highest percentage but problem gamblers were not significantly lower. Further, a significantly higher percentage of problem gamblers were motivated to gamble as a form of therapy or escape compared to most other groups, such as "helps to relax", "takes mind off things that worry me" and "reduce stress, depression and anger". These results could be interpreted in two ways: either the problem gamblers feel motivated to gamble for more reasons, or they are using many motivations to explain their behaviour.

Perhaps the most telling motivation is "addicted to gambling", which $38.9 \%$ of the problem gamblers endorsed, compared with $10.2 \%$ of moderate risk gamblers, $3.2 \%$ of low risk gamblers and $0.3 \%$ of non-problem gamblers. Table 1 shows full comparisons between groups, including significant differences.

\section{PGSI Gambling Behaviour Comparisons}

The PGSI groups engaged in a significantly different number of gambling activities to each other, $F(3,960)=49.16, p<0.001, \eta^{2}=0.13$. Post-hoc comparisons using the Tukey HSD procedure revealed that all groups were significantly different from each other. On average, non-problem gamblers engaged in $3.32(S D=2.06)$ different forms of gambling, compared to low risk gamblers $(M=4.12, S D=2.30)$, moderate risk gamblers $(M=4.97, S D=2.33)$ and problem gamblers $(M=5.66, S D=3.04)$.

Higher proportions of the higher risk than lower risk PGSI groups participated in all forms of gambling surveyed (smallest $\chi^{2}(3, N=962)=15.47, p=0.001, \Phi=0.13$, for scratchies). Thus, all surveyed forms of gambling appear more attractive to those moderate risk and possible problem gamblers, compared to low risk and non-problem gamblers (Table 2). 
Table 1 Comparisons of PGSI categories for gambling motivation

\begin{tabular}{|c|c|c|c|c|c|c|}
\hline $\begin{array}{l}\text { Motivation for } \\
\text { gambling }\end{array}$ & $\begin{array}{l}\text { Non- } \\
\text { problem }\end{array}$ & $\begin{array}{l}\text { Low } \\
\text { risk }\end{array}$ & $\begin{array}{l}\text { Moderate } \\
\text { risk }\end{array}$ & Problem & Chi square result & $\begin{array}{l}\text { Total } \\
\text { sample }\end{array}$ \\
\hline Helps to relax & $28.9 \mathrm{a}$ & $44.9_{\mathrm{b}}$ & $53.4_{\mathrm{b}, \mathrm{c}}$ & $65.6_{c}$ & $\begin{array}{c}\chi^{2}(3, \mathrm{~N}=936)=81.06 \\
p<0.001, \Phi=0.29\end{array}$ & 46.5 \\
\hline Pleasure and fun & $52.7_{\mathrm{a}}$ & $62.2_{\mathrm{a}, \mathrm{b}}$ & $70.2_{\mathrm{b}}$ & $67.2_{\mathrm{b}}$ & $\begin{array}{c}\chi^{2}(3, \mathrm{~N}=937)=20.86 \\
p<0.001, \Phi=0.15\end{array}$ & 61.9 \\
\hline Hobby and interest & $22.3_{\mathrm{a}}$ & $30.1_{\mathrm{a}, \mathrm{b}}$ & $38.2_{\mathrm{b}, \mathrm{c}}$ & $43.4_{c}$ & $\begin{array}{c}\chi^{2}(3, \mathrm{~N}=936)=32.51 \\
p<0.001, \Phi=0.19\end{array}$ & 32.6 \\
\hline Cultural tradition & $4.5 \mathrm{a}$ & $9.0_{\mathrm{a}}$ & $7.8_{\mathrm{a}}$ & $20.1_{\mathrm{b}}$ & $\begin{array}{c}\chi^{2}(3, \mathrm{~N}=936)=39.73 \\
p<0.001, \Phi=0.21\end{array}$ & 10.0 \\
\hline $\begin{array}{l}\text { Reduce stress, } \\
\text { depression, anger }\end{array}$ & $12.7 \mathrm{a}$ & $22.4_{b}$ & $30.7_{b}$ & $45.9_{\mathrm{c}}$ & $\begin{array}{c}\chi^{2}(3, \mathrm{~N}=937)=82.21 \\
p<0.001, \Phi=0.30\end{array}$ & 26.9 \\
\hline $\begin{array}{l}\text { Safe and pleasant } \\
\text { place }\end{array}$ & $13_{\mathrm{a}}$ & $27.6_{\mathrm{b}}$ & $25.5_{\mathrm{b}}$ & $33.2_{\mathrm{b}}$ & $\begin{aligned} \chi^{2}(3, N=936) & =35.29 \\
p<0.001, \Phi & =0.19\end{aligned}$ & 23.4 \\
\hline $\begin{array}{l}\text { Socialize with family } \\
\text { and friends }\end{array}$ & $38.6_{\mathrm{a}}$ & $48.7_{\mathrm{a}, \mathrm{b}}$ & $52.9_{\mathrm{b}}$ & $44.3_{\mathrm{a}, \mathrm{b}}$ & $\begin{array}{c}\chi^{2}(3, N=936)=11.70 \\
p=0.009, \Phi=0.11\end{array}$ & 44.9 \\
\hline $\begin{array}{l}\text { Chance to win extra } \\
\text { money }\end{array}$ & $45.2 \mathrm{a}$ & $47.4_{\mathrm{a}}$ & $66.3_{\mathrm{b}}$ & $63.5_{b}$ & $\begin{aligned} \chi^{2}(3, \mathrm{~N}=937) & =34.35 \\
p<0.001, \Phi & =0.19\end{aligned}$ & 55.0 \\
\hline $\begin{array}{l}\text { Challenge to try beat } \\
\text { the odds }\end{array}$ & $18.1_{\mathrm{a}}$ & $26.9_{\mathrm{a}, \mathrm{b}}$ & $34.8_{\mathrm{b}, \mathrm{c}}$ & $42.2_{\mathrm{c}}$ & $\begin{array}{c}\chi^{2}(3, \mathrm{~N}=936)=43.08 \\
p<0.001, \Phi=0.22\end{array}$ & 29.5 \\
\hline I think I am lucky & $11.7_{\mathrm{a}}$ & $16_{\mathrm{a}, \mathrm{b}}$ & $25.6_{\mathrm{b}, \mathrm{c}}$ & $35.2_{\mathrm{c}}$ & $\begin{array}{c}\chi^{2}(3, \mathrm{~N}=935)=50.65 \\
p<0.001, \Phi=0.23\end{array}$ & 21.6 \\
\hline $\begin{array}{l}\text { Most family and } \\
\text { friends gamble }\end{array}$ & $13.9_{\mathrm{a}}$ & $22.4_{\mathrm{a}, \mathrm{b}}$ & $25.6_{b}$ & $43.4_{c}$ & $\begin{array}{c}\chi^{2}(3, \mathrm{~N}=935)=65.71 \\
p<0.001, \Phi=0.27\end{array}$ & 25.6 \\
\hline Less bored & $18.1_{\mathrm{a}}$ & $30.8_{\mathrm{b}}$ & $37.7_{\mathrm{b}, \mathrm{c}}$ & $45.9_{\mathrm{c}}$ & $\begin{array}{c}\chi^{2}(3, \mathrm{~N}=936)=54.68 \\
p<0.001, \Phi=0.24\end{array}$ & 31.7 \\
\hline $\begin{array}{l}\text { Takes mind off things } \\
\text { that worry me }\end{array}$ & $12.3_{\mathrm{a}}$ & $21.8_{\mathrm{b}}$ & $33.8_{\mathrm{b}}$ & $49.6_{c}$ & $\begin{array}{c}\chi^{2}(3, \mathrm{~N}=936)=102.43 \\
p<0.001, \Phi=0.33\end{array}$ & 28.3 \\
\hline Addicted to gambling & $0.3_{\mathrm{a}}$ & $3.2_{\mathrm{b}}$ & $10.2_{\mathrm{b}}$ & $38.9_{\mathrm{c}}$ & $\begin{aligned} \chi^{2}(3, \mathrm{~N}=935) & =206.11, \\
p<0.001, \Phi & =0.47\end{aligned}$ & 13.0 \\
\hline
\end{tabular}

Figures indicate the percentage of respondents from each PGSI category and the total sample of gamblers who indicated that each motivation is relevant to them. Multiple responses were allowed for this question. For each motivation, PGSI categories that are not significantly different to each other share the same subscript

Further, for every form of gambling, those in the higher risk groups reported participating more often than those in lower risk groups (smallest $\chi^{2}(15, N=105)=30.69$, $p=0.010, \Phi_{\mathrm{C}}=0.31$, for online gambling), except for poker tournaments and bingo. For most gambling forms, approximately $40-55 \%$ of problem gamblers gamble at least weekly, compared with approximately $15-20 \%$ of non-problem gamblers, with the lowrisk and moderate-risk groups falling between these values.

Differences between PGSI groups for fortnightly spend on card games were particularly marked for the problem gamblers, with $39.1 \%$ spending more than $\$ 100$ per fortnight, compared with $15.5 \%$ of moderate risk gamblers, which was the next highest spending group. Overall, differences between groups in fortnightly card spend was significant, $\chi^{2}$ $(21, N=364)=87.82, p<0.001, \Phi_{\mathrm{C}}=0.28$. Problem gamblers were also more likely to gamble on cards with food $\left(\chi^{2}(3, N=291)=13.08, p=0.004, \Phi=0.21\right)$, alcohol $\left(\chi^{2}(3, N=292)=20.22, p<0.001, \Phi=0.26\right)$, cigarettes $\left(\chi^{2}(3, N=292)=18.22\right.$, 
Table 2 Gambling behaviour comparisons of PGSI categories, $(N=962)$

\begin{tabular}{lllllc}
\hline Gambling activity & $\begin{array}{l}\text { Non-problem } \\
\text { gamblers }\end{array}$ & $\begin{array}{l}\text { Low risk } \\
\text { gamblers }\end{array}$ & $\begin{array}{l}\text { Moderate risk } \\
\text { gamblers }\end{array}$ & $\begin{array}{l}\text { Problem } \\
\text { gamblers }\end{array}$ & Total \% \\
\hline Card games & 23.8 & 17.0 & 22.8 & 36.4 & 39.9 \\
Poker machines & 30.9 & 17.4 & 23.4 & 28.3 & 85.4 \\
Keno & 28.7 & 16.6 & 24.9 & 29.8 & 60.1 \\
Horse/dog racing & 27.0 & 16.4 & 25.4 & 31.2 & 47.0 \\
Sports betting & 19.4 & 13.4 & 27.1 & 40.1 & 29.5 \\
Bingo & 26.9 & 12.6 & 23.8 & 36.7 & 30.6 \\
Scratchies & 32.8 & 14.3 & 24.2 & 28.6 & 54.5 \\
Lotteries & 33.3 & 13.7 & 25.4 & 27.6 & 51.6 \\
Table games & 16.8 & 14.1 & 25.5 & 43.6 & 15.5 \\
Online & 14.0 & 9.3 & 21.5 & 55.1 & 11.1 \\
Poker tournaments & 18.9 & 13.2 & 24.5 & 43.4 & 15.9 \\
\hline
\end{tabular}

Figures indicate the percentage of respondents who engage in each type of gambling activity that fall into each PGSI group. Total percentage indicates the percentage of respondents who take part in this activity

$p<0.001, \Phi=0.25)$, other possessions $\left(\chi^{2}(3, N=291)=16.12, p=0.001, \Phi=0.24\right)$ and for favours $\left(\chi^{2}(3, N=291)=12.45, p=0.006, \Phi=0.21\right)$.

The PGSI groups also differed significantly in their usual length of card gambling session, $\chi^{2}(21, N=369)=52.40, p<0.001, \Phi_{\mathrm{C}}=0.22$. Standardised residuals again suggested that, compared with other PGSI groups, the problem gamblers gambled for significantly longer sessions while non-problem gamblers more likely gambled on cards for less than an hour.

Respondents were asked how much the winning pot was worth in the last card game they played in their local area. A Kruskal-Wallis test indicated a significant difference in medians, where problem gamblers (median $=\$ 225$ ) and moderate risk gamblers (med$\operatorname{ian}=\$ 200)$ participated in card games with significantly larger pots than did non-problem $($ median $=\$ 100)$ and low risk gamblers $($ median $=\$ 95), \chi^{2}(3, N=251)=14.49$, $p=0.002, \eta^{2}=0.06$.

When asked about time and money spent on their most frequent gambling activity, the most significant differences indicated that non-problem gamblers gambled for very short time periods, compared with all other gambling groups $\left(\chi^{2}(21, N=936)=278.54\right.$, $p<0.001, \Phi_{\mathrm{C}}=0.32$ ). In contrast, $58.4 \%$ of problem gamblers spent more than $\$ 100$ per week on their most frequent gambling activity, compared to $28.0 \%$ of moderate risk gamblers, $10.6 \%$ of low risk gamblers and $6.0 \%$ of non-problem gamblers, $\chi^{2}$ (21, $N=919)=408.68, p<0.001, \Phi_{\mathrm{C}}=0.38$.

\section{Gambling Cognitions}

Gamblers were asked to respond "agree", "disagree" or "don't know" to four statements about erroneous gambling beliefs. Chi square tests, with standardised residuals, indicated that a significantly higher proportion of problem gamblers (compared with other PGSI groups) agreed "While gambling, after losing many times in a row, you are more likely to win", $\left(\chi^{2}(6, N=907)=66.26, p<0.001, \Phi_{\mathrm{C}}=0.19\right)$, and "If a poker machine hasn't 
paid out in a while then it must be due to pay out", $\left(\chi^{2}(6, N=902)=99.28, p<0.001\right.$, $\left.\Phi_{\mathrm{C}}=0.24\right)$. For the statement "While gambling, you can win more if you use a system or strategy", a significantly higher proportion of problem gamblers agreed compared to nonproblem and low risk gamblers, but there is no significant difference between problem and moderate risk gamblers, $\left(\chi^{2}[6, N=899]=70.11, p<0.001, \Phi_{\mathrm{C}}=0.20\right)$. For the statement "If you continue gambling, in the end you will lose", there was no significant difference between the groups in terms of proportion of respondents who agreed with the statement.

Overall, approximately one-quarter of the gamblers expect a win at the end of a losing streak (42.4\% for problem gamblers), nearly one-third expect a poker machine is due for a win if it hasn't paid out for a while (53.7\% for problem gamblers), while nearly one-quarter agree that a system or strategy can lead to more wins (38.6\% for problem gamblers). However, nearly one-quarter of the gamblers disagreed that if you continue gambling in the end you will lose, with no significant difference between PGSI groups.

\section{Alcohol and Drug Use While Gambling}

Over three-quarters of the problem gamblers $(78.9 \%)$ drink and/or take drugs at least sometimes while gambling, which is significantly higher than all other PGSI groups, $\chi^{2}(3$, $N=950)=199.18, p<0.001, \Phi_{\mathrm{C}}=0.46$. Furthermore, problem gamblers drink and/or take drugs while gambling more often than all other PGSI groups, $\chi^{2}(9, N=950)=$ $220.61, p<0.001, \Phi_{\mathrm{C}}=0.28$, with the problem gamblers doing so "most of the time" $(21.1 \%)$ or "almost always" (16.0\%).

Of those reporting drinking or taking drugs while gambling, $79.8 \%$ said that doing so resulted in them gambling more while under the influence. This figure was significantly higher for problem gamblers $(92.4 \%)$ compared with $75.6 \%$ of moderate risk gamblers, $75.3 \%$ of low risk gamblers and $62.5 \%$ of non-problem gamblers, $\chi^{2}(3, N=481)=$ $35.73, p<0.001, \Phi_{\mathrm{C}}=0.27$.

\section{Characteristics Differentiating Problem Gamblers from Other Gamblers}

A logistic regression investigated the difference between problem gamblers and all other PGSI groups. This split was chosen as most preceding analyses found significant differences between problem gamblers (PGSI score of $8+$ ) and those with PGSI scores $<8$.

Twenty-eight predictors were initially included in the model: gender, age bracket, marital status, work status, state of residence, age of first gamble, whether the respondent uses drugs and/or alcohol while gambling, how often adults gambled around the respondents when they were children, fortnightly spend on most frequent commercial gambling activity, number of commercial gambling behaviours engaged in, motivations for gambling (14 questions) and erroneous gambling beliefs (four questions).

The latter two sets of predictors were treated as blocks and both entered as last steps in separate hierarchical logistic regressions. The erroneous belief variables did not result in a statistically significant increase in model fit $\left(\chi^{2}[4, N=481]=7.508, p=0.111\right)$ and were thus not included in the final model, leaving 24 predictors. Variables in relation to card gambling behaviour could not be included due to high correlations with fortnightly spend on most frequent commercial gambling activity.

Low cell counts for some categorical variables prompted merging of: "widowed" (2.1\% of respondents) with "separated/divorced" (7.4\%); first gambled when less than 5 years old $(3.2 \%)$ with first gambled when 5-9 years old $(6.2 \%)$; state of residence as 
New South Wales, Queensland or "other"; and source of income as "work only" (65.3\%), "pension only" (31.4\%) and "other" (3.3\%),

Reference categories for the categorical variables were: gender (male), marital status (married), source of income (work only), state of residence (NSW), age of first gamble (18 years+), gambling under the influence of alcohol or drugs (never), how often parents gambled around their children (never) and (no) for all gambling motivation variables. The model, including all appropriately dummy-coded categorical variables, was run through a linear regression (DV: PGSI score) to check for possible multicollinearity issues. While the lowest tolerance value was 0.484 (for one gambling motivations variable), this is within guidelines (Keith 2005). All other tolerance values were above 0.5, with most above 0.7.

Respondents with missing values for any predictors were removed from this analysis, leaving 718 respondents ( $74.5 \%$ of gamblers in the survey). The model was statistically significant, $\left(\chi^{2}[34, N=718]=343.06, p<0.001\right)$, indicating that the model as a whole reliably distinguishes problem gamblers from other gamblers. Overall prediction success is $86.8 \%$. The model correctly predicted $94.4 \%$ of non-problem gamblers and $63.9 \%$ of problem gamblers.

Controlling for all other variables in the model, the significant predictors that differentiate problem gamblers from other gamblers were: age (older gamblers are more likely to be problem gamblers), state of residence (those who live in states other than NSW and Queensland), those who first gambled when they were under 10 years old, any level of alcohol and/or drug use while gambling (compared to none), gamblers who were always exposed to adults gambling when they were children, level of expenditure on commercial gambling activities, those who do not gamble to socialise, those whose family and friends gamble, and those who gamble because they are addicted. Table 3 summarises these results. ${ }^{1}$

\section{Discussion and Implications}

This study has provided the first comprehensive quantitative analysis of problem gambling risk factors amongst Indigenous Australians, drawing on the largest sample to date. Despite the convenience sampling, valid comparisons amongst PGSI groups were able to be conducted, even if the prevalence of the identified risk factors might vary from those which might be attained in a random, representative survey. Thus, the study identifies a range of problem gambling risk factors that can inform appropriately targeted public health interventions relevant to Indigenous Australians.

Some problem gambling risk factors identified for the Indigenous respondents in this study, such as substance use while gambling, having family and friends who gamble, gambling alone and not for social reasons, and high gambling expenditure, are also well documented risk factors for the general population (Johansson et al. 2009). Although these are significant, our discussion emphasises the less well recognised and distinctive cultural risk factors to bring them to the attention of Indigenous communities and public health policy makers. Doing so is important as these risk factors are associated with very high

\footnotetext{
${ }_{1}$ Due to the possibly arbitrary nature of the dependent variable in the logistic regression, the model was also run as a multiple linear regression and explained $58.8 \%$ of the variance in PGSI scores $(F[34,686]=28.78$, $p<0.001$ ). The only change to significant predictors was for gender (females more likely to be problem gamblers, holding constant all other variables) and for those who first gambled between 10 and 14 years of age. All other predictors were as for the logistic regression.
} 
Table 3 Logistic regression of characteristics differentiating problem gamblers from non-problem gamblers for $N=718$

\begin{tabular}{|c|c|c|c|c|c|}
\hline Predictor & B & $\begin{array}{l}\text { Std } \\
\text { error (B) }\end{array}$ & Wald & Sig & $\begin{array}{l}\text { Odds } \\
\text { ratio }\end{array}$ \\
\hline Gender & 0.150 & 0.267 & 0.314 & 0.576 & 1.162 \\
\hline Age & 0.127 & 0.057 & 4.916 & 0.027 & 1.136 \\
\hline Marital Status (reference: married) & & & 6.310 & 0.097 & \\
\hline Living with partner & -0.478 & 0.366 & 1.699 & 0.192 & 0.620 \\
\hline Single & -0.488 & 0.339 & 2.070 & 0.150 & 0.614 \\
\hline Separated/divorced/widowed & 0.496 & 0.451 & 1.210 & 0.271 & 1.642 \\
\hline Work status (reference: work only) & & & 1.815 & 0.404 & \\
\hline Pension only & 0.175 & 0.283 & 0.383 & 0.536 & 1.192 \\
\hline Other & 0.726 & 0.565 & 1.654 & 0.198 & 2.067 \\
\hline State of Residence (reference: NSW) & & & 6.238 & 0.044 & \\
\hline Queensland & -0.126 & 0.314 & 0.161 & 0.688 & 0.881 \\
\hline Other & 0.916 & 0.391 & 5.482 & 0.019 & 2.499 \\
\hline Age of first gamble (reference: $18+$ ) & & & 11.441 & 0.010 & \\
\hline Under 10 years old & 1.311 & 0.401 & 10.698 & 0.001 & 3.712 \\
\hline $10-14$ years old & 0.027 & 0.457 & 0.003 & 0.954 & 1.027 \\
\hline $15-17$ years old & 0.396 & 0.330 & 1.445 & 0.229 & 1.486 \\
\hline Alcohol and drugs while gambling (reference: never) & & & 23.349 & $<0.001$ & \\
\hline Sometimes & 1.418 & 0.301 & 22.184 & $<0.001$ & 4.129 \\
\hline Most of the time & 0.898 & 0.405 & 4.927 & 0.026 & 2.455 \\
\hline Almost always & 1.386 & 0.518 & 7.158 & 0.007 & 4.000 \\
\hline Childhood exposure to gambling (reference: never) & & & 12.369 & 0.006 & \\
\hline Sometimes & 0.265 & 0.367 & 0.520 & 0.471 & 1.303 \\
\hline Most of the time & 0.630 & 0.430 & 2.145 & 0.143 & 1.877 \\
\hline Always & 1.291 & 0.420 & 9.453 & 0.002 & 3.635 \\
\hline Expenditure on favorite commercial gambling activity & 0.524 & 0.079 & 44.148 & $<0.001$ & 1.689 \\
\hline Number of different commercial gambling activities & 0.097 & 0.053 & 3.338 & 0.068 & 1.102 \\
\hline Main reasons for gambling & & & 65.01 & $<0.001$ & \\
\hline Helps to relax & 0.340 & 0.289 & 1.389 & 0.239 & 1.405 \\
\hline Pleasure and fun & -0.172 & 0.300 & 0.330 & 0.566 & 0.842 \\
\hline Hobby and interest & -0.412 & 0.300 & 1.883 & 0.170 & 0.663 \\
\hline Cultural tradition & -0.659 & 0.441 & 2.239 & 0.135 & 0.517 \\
\hline Reduce stress, depression, anger & 0.569 & 0.337 & 2.842 & 0.092 & 1.766 \\
\hline Safe and pleasant place & 0.342 & 0.334 & 1.050 & 0.306 & 1.408 \\
\hline Socialize with family and friends & -0.776 & 0.301 & 6.634 & 0.010 & 0.460 \\
\hline Chance to win extra money & -0.509 & 0.292 & 3.040 & 0.081 & 0.601 \\
\hline Challenge to try to beat the odds & -0.117 & 0.318 & 0.135 & 0.714 & 0.890 \\
\hline I think I am lucky & -0.064 & 0.343 & 0.034 & 0.853 & 0.938 \\
\hline Most family and friends gamble & 0.832 & 0.326 & 6.526 & 0.011 & 2.298 \\
\hline Less bored & -0.283 & 0.319 & 0.786 & 0.375 & 0.753 \\
\hline Takes mind off things that worry me & 0.429 & 0.333 & 1.657 & 0.198 & 1.535 \\
\hline I am addicted to gambling & 1.963 & .375 & 27.363 & $<0.001$ & 7.121 \\
\hline
\end{tabular}

Significant predictors in bold 
rates of problem gambling in this Indigenous sample, as also found in other Indigenous gambling research (Alegría et al. 2009; Belanger 2011; Gray 2011; Ministry of Health 2009; Williams et al. 2011; Stevens and Young 2009).

Compared to Australian population estimates (Productivity Commission 2010), our sample contained a slightly higher proportion of gamblers, over eight times the proportion of moderate risk gamblers, and over 19 times the proportion of problem gamblers. Almost half of all research participants $(48.6 \%)$ and nearly two-thirds of all gamblers were at some level of risk with their gambling. Because gambling impacts extend to families and communities, and because Indigenous Australians belong to a collectivist-style culture that particularly values relationships and community, programs to prevent gambling problems, protect vulnerable people and promote responsible gambling should be designed to assist everyone in Indigenous communities. These programs are vital, because once a person starts gambling, they appear unlikely to avoid gambling problems. A coalition of local Indigenous groups and public health decision makers could jointly design and implement appropriate public health programs for maximum effectiveness.

The prevalence rates in this study are comparable to overseas Indigenous populations, being within the range (10-20\%) reported for North American Aboriginal and First Nations people (Currie 2011; Wardman et al. 2001; Williams et al. 2011; Wynne and McCready 2005), which in turn are higher than for New Zealand Maori and Pacific peoples (Ministry of Health 2009). These similarities suggest that the circumstances common to many Indigenous populations may pose distinctive risks for gambling problems. Thus, successful public health interventions in non-Australian Indigenous communities might inform those for Indigenous Australians. Although not directly investigated in our study, the considerable disadvantage experienced by many Indigenous people may encourage the development of addictive behaviours (Williams et al. 2011). While improving structural conditions and reversing social disadvantage for Indigenous Australians are long-term processes driven by government policies, public health decision-makers can act within much shorter time frames to redress adverse gambling consequences.

In this study, the only significant socio-demographic risk factor was being older, not younger. This finding contradicts previous Indigenous gambling research based on convenience samples (Dickerson et al. 1996), representative samples (Anctil and Chevalier 2003), and in secondary analysis of national data (Stevens and Young 2009). Reviews of general population studies have also noted young age as a problem gambling risk factor (Delfabbro 2009; Johansson et al. 2009). Nevertheless, our findings suggest that health strategies should also be aimed at older Indigenous people (Elders, senior groups) and emphasise their status as community role models.

Early exposure to gambling, including frequent exposure to adults gambling when a child, and commencing gambling when under 10 years, were significant risk factors for gambling problems in our study. In some Indigenous Australian communities, childhood exposure to gambling occurs with card gambling (CIRCA 2011; Hunter and Spargo 1988), which is part of the 'social fabric' of some Indigenous communities (Queensland Department of Corrective Services 2005:29), and a popular recreational activity (AHMRC 2007). At the card site, children often watch games, mind smaller children and wait for games to end (McDonald and Wombo 2006). Links between early exposure to gambling and gambling problems were also found by the Queensland Department of Corrective Services (2005) where Indigenous moderate risk and problem gamblers were more likely to report growing up in households where adults 'always' or 'often' gambled. Similarly, international findings link exposure of young Indigenous people to gambling to later gambling problems (SHORE and Whariki 2008; Smith et al. 2011; Westermeyer et al. 
2005). In our study, early uptake of gambling was also statistically associated with gambling problems in later life. Gambling by Indigenous youth has been reported in Australia (Delfabbro et al. 2005; QLD Department of Corrective Services 2005) and internationally (Dyall and Hand 2003; Morrison 1999; Welte et al. 2007; Williams et al. 2011). Thus, common experiences of underage gambling found amongst our sample appear to be shared by other Indigenous people, and may be facilitated by the popularity of unregulated forms of gambling such as card games.

This study provides the first empirical evidence linking regular and constant exposure to gambling as a child and commencing gambling under the age of 10 years to later gambling problems amongst Indigenous Australian adults. High rates of problem gambling, exposure of children to gambling, and opportunities to commence gambling when very young all suggest that the intergenerational transfer of gambling problems may be particularly marked amongst some Indigenous peoples. Such serious and potentially damaging longterm consequences deserve maximum attention from public health decision makers through the implementation of appropriate community education. A failure to address this key finding could lead to continuing gambling problems for future generations, given that each new 'case' of problem gambling increases the likelihood of future cases (Productivity Commission 2010). Addressing gambling problems amongst today's Indigenous adults should reduce gambling problems in future generations.

In response to other risk factors identified in this study, appropriate health promotion messages could be introduced to dispel erroneous beliefs around gambling, educate people about the processes involved in gambling and discourage substance use while gambling. Combined public health programs for alcohol, drug and gambling services should be provided for those needing them. Further, as gambling is generally conducted in licensed venues, responsible service of alcohol should be emphasised along with responsible gambling.

\section{Conclusion}

This study into problem gambling risk factors amongst Indigenous Australians has added to the growing body of evidence that indicates much higher rates of gambling problems amongst Indigenous peoples, compared to non-Indigenous peoples. By identifying the risk factors associated with problem gambling amongst a sample of Indigenous Australians, we hope that this study will inform public health interventions aimed at reducing these risk factors to address this serious and urgent public health issue.

Acknowledgments We deeply appreciate the cooperation and collaboration of many Indigenous Australian people who assisted us with this research. Funding for this study was received from the Australian Research Council.

\section{References}

Aboriginal Health \& Medical Research Council of NSW (AHMRC). (2007). Pressing problems: Gambling issues and responses for NSW aboriginal communities. Sydney: Aboriginal Health \& Medical Research Council of NSW (AHMRC).

Alegría, A., Petry, N., Hasin, D., Liu, S.-M., Grant, B., \& Blanco, C. (2009). Disordered gambling among racial and ethnic groups in the US: Results from the national epidemiologic survey on alcohol and related conditions. CNS Spectrums, 14(3), 132-142. 
Atkinson, J. (2002). Trauma trails recreating songlines: The transgenerational effects of trauma in Indigenous Australia. Melbourne: Spinifex Press.

Australian Bureau of Statistics. (2006). National Aboriginal and Torres Strait Islander health survey 2004-05: Catalogue No. 4715.0. Canberra: Australian Bureau of Statistics.

Australian Institute of Aboriginal and Torres Strait Islander Studies (AIATSIS). (2012). Guidelines for ethical research in Australian Indigenous studies. Canberra: Australian Institute of Aboriginal and Torres Strait Islander Studies (AIATSIS).

Belanger, Y. (2011). First nations gaming in Canada. Winnipeg: University of Manitoba Press.

Binde, P. (2005). Gambling across cultures: Mapping worldwide occurrence and learning from ethnographic comparison. International Gambling Studies, 5(1), 1-27.

Breen, H. (2008). Visitors to northern Australia: Debating the history of indigenous gambling. International Gambling Studies, 8(2), 137-150.

Breen, H., Hing, N., \& Gordon, A. (2011). Indigenous gambling motivations, behaviour and consequences in Northern New South Wales, Australia. International Journal of Mental Health and Addiction, 9(6), $723-739$.

Australian Bureau of Statistics. (2010). Population by age and sex, Australian states and territories, 2010: Catalogue 3201.0. Canberra: Australian Bureau of Statistics.

Australian Bureau of Statistics. (2012). Census of population and housing-counts of aboriginal and torres strait islander Australians, 2011: Catalogue 2075.0. Canberra: Australian Bureau of Statistics.

Productivity Commission. (2010). Gambling: Report no. 50. Canberra: Productivity Commission.

Cultural \& Indigenous Research Centre Australia (CIRCA). (2011). Development of culturally appropriate problem gambling services for Indigenous communities, Occasional Paper No. 40. Canberra: Commonwealth of Australia.

Cultural Perspectives Pty. Ltd. (2005). Problem gambling research report for Indigenous communities. Melbourne: Victorian Department of Justice.

Currie, C. (2011). How is problem gambling impacting urban Aboriginal Peoples? Paper presented at the Alberta Gaming Research Institute Conference, Banff, Alberta, April.

Delfabbro, P. (2009). Australasian gambling review (4th ed.). Adelaide: Independent Gambling Authority of South Australia.

Delfabbro, P., Lahn, J., \& Grabosky, P. (2005). Adolescent gambling: A report on recent ACT research. Canberra: ACT Gambling and Racing Commission.

Dickerson, M., Allcock, C., Blaszczynski, A., Nicholls, B., Williams, J., \& Maddern, R. (1996). A preliminary exploration of the positive and negative impacts of gambling and wagering on aboriginal people in NSW. Sydney: Australian Institute of Gambling Research.

Dion, J., Collin-Vézina, D., De La Sablonnière, M., Philippe-Labbé, M. P., \& Giffard, T. (2010). An exploration of the connection between child sexual abuse and gambling in aboriginal communities. International Journal of Mental Health and Addiction, 8(2), 174-189.

Dyall, L., \& Hand, J. (2003). Maori and gambling: Why a comprehensive maori public-health response is required in New Zealand. International Journal of International Mental Health \& Addiction, 1(1), $1-16$.

Ferris, J., \& Wynne, H. (2001). The Canadian problem gambling index: Final report. Ottawa: Canadian Centre on Substance Abuse.

Gainsbury, S., \& Breen, H. (2013). Literature review of Aboriginal problem gambling and research direction recommendations. Guelph: Ontario Problem Gambling Research Centre.

Gray, R. (2011). New Zealanders' participation in gambling: Results from the 2010 health and lifestyles survey. Wellington: Health Sponsorship Council.

Hare, S. (2009). A study of gambling in victoria: Problem gambling from a public health perspective. Melbourne: Department of Justice.

Hing, N., Breen, H., Gordon, A., \& Russell, A. (2013). The gambling behavior of Indigenous Australians. Journal of Gambling Studies. doi:10.1007/s10899-013-9358-9.

Holland, C. (2011). Shadow report: On Australian governments' progress towards closing the gap in life expectancy between Indigenous and non-Indigenous Australians. Canberra: Close the Gap Campaign Steering Committee.

Hunter, E., \& Spargo, R. (1988). What's the big deal? Aboriginal gambling in the kimberley region. The Medical Journal of Australia, 149, 668-672.

Johansson, A., Grant, J., Kim, S., Odlaug, B., \& Gunnar, K. (2009). Risk factors for problematic gambling: A critical literature review. Journal of Gambling Studies, 25(1), 67-92.

Keith, T. (2005). Multiple regression and beyond. Boston: Pearson Education.

Martin, K. (2008). Please knock before you enter, Aboriginal regulation of outsiders and the implications for researchers. Brisbane: Post Pressed. 
McDonald, H., \& Wombo, B. (2006). Indigenous gambling scoping study-Draft report. Darwin: Charles Darwin University.

McMillen, J., \& Donnelly, K. (2008). Gambling in Australian indigenous communities: The state of play. Australian Journal of Social Issues, 43(3), 397-426.

McMillen, J., Marshall, D., Murphy, L., Lorenzen, S., \& Waugh, B. (2004). Help-seeking by gamblers, friends and families in the ACT: A focus on cultural and gender issues. Canberra: ACT Gambling and Racing Commission.

Ministry of Health. (2009). A focus on problem gambling: Results of the 2006/07 New Zealand health survey. Wellington: Ministry of Health.

Morrison, L. (1999). The good and the bad times: Maori women's experiences of gambling in Rotorua. Unpublished Masters thesis, University of Waikato, Hamilton, NZ.

National Health and Medical Research Council (NHMRC). (2003). Values and ethics: Guidelines for ethical conduct in aboriginal and torres strait islander health research. Canberra: National Health and Medical Research Council (NHMRC).

National Health and Medical Research Council (NHMRC). (2007). National statement on ethical conduct in human research. Canberra: National Health and Medical Research Council (NHMRC).

Penfold, A., Hatcher, S., Sullivan, S., \& Collins, N. (2006). Gambling problems and attempted suicide: Part 11-Alcohol abuse increases suicide risk. International Journal of Mental Health and Addiction, 4, 273-279.

Perese, L., Bellringer, M., \& Abbott, M. (2005). Literature review to inform social marketing and approaches, and behaviour change indicators, to prevent and minimise gambling harm. Wellington: Health Sponsorship Council.

Productivity Commission. (1999). Australia's gambling industries: Report no. 10. Canberra: Ausinfo.

Queensland Department of Corrective Services. (2005). Games people play: Problem gambling in Queensland community corrections. Brisbane: Queensland Department of Corrective Services.

Queensland Government. (2008). Queensland household gambling survey 2006-07. Brisbane: Queensland Government.

Queensland Government. (2010). Evaluation of the Queensland responsible gambling strategy. Brisbane: Queensland Government.

Shaffer, H., \& Korn, D. (2002). Gambling and related mental disorders: A public health analysis. Annual Review of Public Health, 23, 171-212.

SHORE \& Whariki. (2008). Assessment of the social impacts of gambling in New Zealand. Auckland: SHORE \& Whariki.

Smith, G., Currie, C., \& Battle, J. (2011). Exploring gambling impacts in two Alberta Cree communities: A participatory action study. In Y. Belanger (Ed.), First Nations gambling in Canada: Current trends and issues (pp. 118-139). Winnipeg: University of Manitoba Press.

Stevens, M., \& Young, M. (2009). Reported gambling problems in the Indigenous and total Australian population. Melbourne: Gambling Research Australia.

Tse, S., Dyall, L., Clarke, D., Abbott, M., Townsend, S., \& Kingi, P. (2010). Why people gamble: A qualitative study of four New Zealand ethnic groups. International Journal of Mental Health and Addiction,. doi:10.1007/s11469-012-9380-7.

Volberg, R. (1994). The prevalence and demographics of pathological gamblers: Implications for public health. American Journal of Public Health, 84(2), 237-241.

Wardman, D., el-Guebaly, N., \& Hodgins, D. (2001). Problem and pathological gambling in North American aboriginal populations: A review of the empirical literature. Journal of Gambling Studies, $17(2), 81-100$.

Welte, J., Barnes, G., Wieczorek, W., Tidwell, M., \& Hoffman, J. (2007). Type of gambling and availability as risk factors for problem gambling: A Tobit regression analysis by age and gender. International Gambling Studies, 7(2), 183-198.

Westermeyer, J., Canive, J., Garrard, J., Thuras, P., \& Thompson, J. (2005). Lifetime prevalence of pathological gambling among American Indian and Hispanic American veterans. American Journal of Public Health, 95, 860-866.

Williams, R., Stevens, R., \& Nixon, G. (2011). Gambling and problem gambling in North American Aboriginal People. In Y. Belanger (Ed.), First Nations gambling in Canada: Current trends and issues (pp. 166-194). Winnipeg: University of Manitoba Press.

Wynne, H., \& McCready, J. (2005). Examining gambling and problem gambling in Ontario Aboriginal communities. Ontario: Ontario Problem Gambling Research Centre. 